\title{
Is free choice for cesarean section really free?
}

| ${ }^{1}$ Jane A. Russo I

1 Instituto de Medicina Social, Universidade do Estado do Rio de Janeiro. Rio de Janeiro-RJ, Brazil (jane.russo@gmail.com). ORCID: 0000-0002-4383-334X

DOI: http://dx.doi.org/10.1590/S0103-73312019290301

A research conducted by Fiocruz between 2011 and 2012 investigated 23,894 women with the aim of knowing the determinants, magnitude and effects of obstetric interventions in childbirth and to estimate the prevalence of caesarean sections in institutions of the Brazilian health system. The results were impressive. At that time, $52 \%$ of deliveries in Brazil were cesarean sections. In the private sector, the numbers were alarming: $88 \%-46 \%$ in the public sector. These numbers have made our country a world champion in performing cesarean sections, contrary to what has been advocated by the World Health Organization (WHO) since at least 1985, and also keeping us away from obstetric practices in countries with strong tradition in quality public services such as the United Kingdom and Canada (LEAL et al., 2014).

Last August, the Legislative Assembly of the State of Sáo Paulo approved Bill No. 435, authored by Mrs Janaina Paschoal, whose purpose would be to guarantee the pregnant woman the possibility to opt for cesarean section, from the thirtyninth week of pregnancy, independently of indication for normal delivery. In the justifications presented, the following argument is stated: "Individual autonomy gives the pregnant woman the right, well advised by the accompanying physician, to choose the preferred delivery route; the complications at the moment of delivery will be taken into account in order to, eventually, take a different path from that originally intended". The bill, despite not having obtained the approval 
of technical committees, was approved. The women and health professionals movement that fights for humanized childbirth in Brazilian maternity hospitals fiercely opposed the new law.

The law seemingly seeks to defend the autonomy of women and their right to free choice - in this case, the mode of delivery. Interestingly, in her Facebook post, in defense of her project, the congresswoman cites the article "The decision for the way of delivery in Brazil: themes and trends in the production of public health", by Liana Carvalho Riscado, Claudia Bonan Janotti and Regina Barbosa, which makes an integrative literature review study on the "decision" related to the mode of delivery in the field of Collective Health. However, there is nothing in the article by Riscado, Janotti and Barbosa (2016) to justify a defense of the option for cesarean section, much less the argument used by the congresswoman that the decision (by cesarean section) is respected when it comes to middle class women. The same would not be true for women from popular classes served by Brazilian Public Health System (SUS). It would therefore be a privilege denied to women of the lower classes. The authors use the categories "decision", "choice" and "preference" in quotation marks, precisely because these should be problematized.

The choice of a woman's birth route does not occur in a socio-cultural void. On the contrary, the pregnant woman is immersed in a social and cultural context in which vaginal delivery and caesarean section can be imagined, reported, portrayed and experienced quite differently. Given the WHO recommendation that cesarean sections shouldn't exceed $15 \%$ of all deliveries, the Brazilian numbers are absurd. And they certainly do not correspond to a "free choice" by the vast majority of pregnant women, especially those who give birth in the private sector. How should we understand our statistics, so divergent from more advanced countries in terms of women's health care and with low rates of maternal morbidity and mortality? The survey conducted by Riscado, Janotti and Barbosa (2016) points out some reflections that help us rethink the choice issue.

Most women in both the public and private sectors start their pregnancies wanting a vaginal delivery, but at the end of it, they opt for or accept a caesarean section. What happens midway? The survey brings the results of research that shows the medical preference (and not the pregnant woman's) for cesarean section. Issues such as "cord loop" or baby size, for example, may be considered sufficient to indicate surgery. In addition, medical students seem to lack adequate training in the 
management of vaginal delivery, which will lead them to indicate a cesarean section for fear of more imagined than real complications. In addition, there are, of course, the economic interests of health insurance, the comfort of a timely procedure, and the lack of structure of many public services to adequately assist vaginal delivery.

How can we speak of the "right to free choice of women" in such an obviously "pro-cesarean" context, in which the medical preference for cesarean section cannot be underestimated? How does a woman have access to a "free choice" if, during her prenatal care, information is provided by obstetricians who are often hostile or fearful of vaginal delivery? How can we speak of "decision" or "preference" when the woman in labor is often humiliated, abused? When invasive and unnecessary procedures are performed by overworked medical staff that has no time (and sometimes no desire) to treat women in a humane and welcoming manner at a delicate moment of their lives? How can one not understand that a woman without resources, without information, faced with such a situation does not end up preferring a caesarean section? As long as it is quick, painless and frees her from an often traumatic situation?

Cesarean section, in which the child is removed from the mother's womb through surgery, should undoubtedly be considered a medical breakthrough, which has saved and still saves many lives of women and babies. But its indication is precise, and, like any other surgery, it involves risks and should be avoided when not necessary. There is a great deal of scientific research demonstrating the disadvantage of cesarean section compared to normal birth - both for maternal and baby's health. Its trivialization should not be naturalized, and the "choice" of pregnant women should be analyzed as one of the products of this trivialization, as well as of the diffuse praise of medical technological interventions that we see today. The proper economic and market value of such interventions should be part of our analysis, helping us to think about the (mis)route followed by obstetrics in Brazil.

I am sure that Mrs Janaina Paschoal also felt a tender emotion looking at the picture of the Duchess of Windsor, Kate Middleton, calmly smiling beside her husband in April 2018 at the door of the hospital where she had given birth to the royal prince just six hours earlier, in a normal birth assisted by a midwife. Yes, we imagine that if Kate had requested that her delivery be performed through a caesarean section her wish would be granted. But in order to understand how "free choices" are produced, one must understand that in the context in which the duchess 
lives, births are delivered by midwives and babies are born naturally through vaginal birth. They are not medical events, they are not seen as a medical intervention. So the "free choice" for a cesarean section is not even on the horizon. It is not prohibited, but it simply does not occur. Or it occurs marginally (far from our $88 \%$ of sections in the private sector) - because it is not part of the social imaginary. It's as simple as that. The woman is not taught, or even indoctrinated, to fear normal childbirth, so the cesarean section does not appear as a solution to a problem, because the problem was not created...

The São Paulo congresswoman would certainly be working for women's rights if she used her mandate not to argue for the "right to choose a cesarean section", but to guarantee the pregnant woman's right to be respected and carefully assisted when giving birth. For the right to have a companion by her side to give her peace of mind and support. To be very knowledgeable about what happens during birth. To be informed about the real advantages and disadvantages of a cesarean section.

Only after normalizing normal birth - an action that requires a lot of work with hospitals, doctors, medical associations, politicians, the media and other key players - can we talk about "choosing the way of delivery". Until then, it is up to all of us public health professionals to prevent apparently free choices from being made with a blindfold.

\section{References}

RISCADO, L. C.; JANNOTTI, C. B.; BARBOSA, R. H. S. Decisão pela via de parto no brasil: temas e tendências na produção da saúde coletiva. Texto Contexto Enferm, v. 25, n. 1, p. e3570014, 2016 (http://dx.doi.org/10.1590/0104-0707201600003570014).

LEAL, M. C. et al. Sumário Executivo Temático da Pesquisa Nascer no Brasil. Rio de Janeiro: Fiocruz, 2014. Disponível em: <http://www.ensp.fiocruz.br/portal-ensp/informe/site/arquivos/ anexos/nascerweb.pdf $>$. Acesso em: set. 2019. 